\title{
Usefulness of Mid-Upper Arm Circumference in Assessment of Nutritional Status of Elderly Persons in Urban India
}

\author{
Anil Kumar Goswami ${ }^{1}$, Mani Kalaivani², Sanjeev Kumar Gupta ${ }^{3}$, Baridalyne Nongkynrih*3, \\ Chandrakant S. Pandav ${ }^{4}$
}

\section{Anil Kumar Goswami ${ }^{1}$, Mani Kalaivani' ${ }^{2}$, Sanjeev Kumar Gupta ${ }^{3}$, Baridalyne Nongkynrih*3, Chandrakant S. Pandav ${ }^{4}$}

\begin{abstract}
'Assistant Professor, Centre for Community Medicine, All India Institute of Medical Sciences, New Delhi, INDIA. ${ }^{2}$ Department of Biostatistics, All India Institute of Medical Sciences, New Delhi, INDIA.

${ }^{3}$ Professor, Centre for Community Medicine, All India Institute of Medical Sciences, New Delhi, INDIA.

${ }^{4}$ Professor and Head, Centre for Community Medicine, All India Institute of Medical Sciences, New Delhi, INDIA.
\end{abstract}

\section{Correspondence}

\section{Dr Baridalyne Nongkynrih}

Old O.T. Block, Centre for Community Medicine, All India Institute of Medical Sciences, New Delhi, INDIA. Mobile no: 91-11-26593789

Email: baridalyne@gmail.com

\section{History}

- Submission Date: 25-08-2017

- Revised Date: 09-12-2017

- Accepted Date: 25-01-2018

DOI : 10.5530/ijmedph.2018.1.7

Article Available online

http://www.ijmedph.org/v8/i1

\section{Copyright}

(c) 2018 Phcog.Net. This is an openaccess article distributed under the terms of the Creative Commons Attribution 4.0 International license.

\begin{abstract}
The study was done to find out the association between mid-upper arm circumference (MUAC) and body mass index (BMI) and to estimate the cut-off values of MUAC in elderly. Methods: A community-based cross-sectional study was done in a resettlement colony in Delhi. Persons aged 60 years and above were selected by cluster random sampling. House-to-house visits were made, and weight, arm span, mid-upper-arm circumference were measured. Mid-upper arm circumference and body mass index of participants are expressed as mean \pm standard deviation (SD). Scatter diagrams and regression lines were plotted to study the relationships. Receiver operating characteristics (ROC) analysis was done and area under ROC curve was assessed. The sensitivity and specificity for different values of mid-upper arm circumference was calculated. Results: 711 elderly persons were recruited. Positive correlation was seen between BMI and MUAC in men and women ( $r=0.76)$, with 0.67 in men and 0.76 in women $(p<0.001)$. Cut-off values for detecting undernutrition were explored by ROC. In men, 25.7 $\mathrm{cm}$ yielded sensitivity and specificity of $80.2 \%$ and $78.6 \%$ respectively, AUC $(95 \% \mathrm{Cl})$ was $0.85(0.80,0.90)$. In women, with a cut-off $24.3 \mathrm{~cm}$ both the sensitivity and specificity were $79 \%$, AUC $(95 \% \mathrm{Cl})$ was $0.86(0.81,0.91)$. Conclusion: The study authenticates that MUAC correlates positively and significantly with BMI. MUAC values of $25.7 \mathrm{~cm}$ in men and $24.3 \mathrm{~cm}$ in women are useful cut-off points for undernutrition, while $28.5 \mathrm{~cm}$ in men and $27.5 \mathrm{~cm}$ in women could be useful for overweight/obesity.
\end{abstract}

Key words: Mid-upper arm circumference, Elderly, India, Nutritional status, Body mass index.

\section{INTRODUCTION}

Nutrition plays an essential role in health outcomes of older persons. Anthropometric appraisal has always been the preferred method of nutritional evaluation for determining malnutrition, overweight and obesity. It has the advantages of being portable, non-invasive, inexpensive, and simple to use. ${ }^{1}$ The World Health Organization Expert Committee had also recommended anthropometric data collection of adults aged 60 years and above. ${ }^{2}$ Most studies use body mass index as the indicator for assessing nutritional status in all age groups. However, in elderly persons, the process of measuring weight and height may not always be possible. In clinical settings, when a patient is bed-ridden or incapacitated, measurement of weight may be a challenge. Similarly, due to ageing process which results in change of body composition, such as loss of height and weight, muscular and fat mass, body mass index may not be a true indicator of nutritional status in elderly persons. ${ }^{3}$ Studies from Indonesia, Canada and Mexico suggest that mid-upper arm circumference could be a proxy indicator for nutritional status in elderly persons. ${ }^{1,3,4}$ In India, there is limited published data on its usefulness among elderly persons. Hence, there is a need to

carry out similar research in urban elderly population in India. This study was conducted with the objective of studying the association between mid-upper arm circumference and body mass index among elderly persons of Delhi, and to estimate the cut-off values of mid-upper arm circumference in detecting undernutrition and overweight/obesity.

\section{MATERIAL AND METHODS}

A community-based cross-sectional study was done in 2015 in Dakshinpuri Extension, Dr. Ambedkar Nagar, Delhi, a resettlement colony. Ambulatory persons aged 60 years and above, who were residents of the study area for at least the past six months were included in the study. Those who were too ill to participate were excluded. Sample size calculation was done for a population correlation coefficient of 0.5 , sample correlation coefficient of 0.4 , power of $90 \%$, and alpha of $5 \%$. As there is no study in Indian context reporting the correlation between BMI and MUAC in elderly population, we assumed a correlation coefficient of 0.50 in the population which gives highest sample size. Anticipating a correlation coefficient 0.4 in the sample with $90 \%$ power and $5 \%$ level 
of significance, the estimated sample size was 669 elderly persons. The formula used to estimate the sample size ${ }^{6}$ is $n=(z 1-\alpha / 2+z 1-\beta) 2 /(F(r 1)-$ $\mathrm{F}(\mathrm{r} 0)) 2$, where $\left.\mathrm{F}(\mathrm{r} 1)=1 / 2^{\star} \ln ((1+\mathrm{r} 1) / 1-\mathrm{r} 1)\right)$ and $\mathrm{F}(\mathrm{r} 0)=1 / 2^{\star} \ln ((1+\mathrm{r} 0) / 1$ $\mathrm{r} 0)), \mathrm{z} 1-\alpha / 2=1.96$ and $\mathrm{z} 1-\beta=1.28$. Cluster random sampling was done where each block was one cluster. All elderly persons in the randomly selected three blocks were recruited to the study. House-to-house visits were made, and measurement of weight, arm span, mid-upper-arm circumference were done using standard procedures as per the World Health Organisation (1995) guidelines. ${ }^{2}$ Body Mass Index (BMI) was derived from weight and arm span; BMI = weight $(\mathrm{kg}) / \mathrm{arm}$ span $\left(\mathrm{m}^{2}\right)$. In elderly persons, arm span is a better proxy measure for height, because as a result of increased spinal curvature and postural problems, accurate measurement of height is difficult. Studies have shown that arm span correlates highly with height, and can be used as its substitute in elderly persons. ${ }^{7,8,9,10,11,12}$ As per guidelines of the World Health Organization, under-nutrition was defined as a body mass index (BMI) of less than $18.5 \mathrm{~kg} / \mathrm{m}^{2}$; overweight was defined as BMI $25.0-29.9 \mathrm{~kg} / \mathrm{m}^{2}$, and obesity as BMI $\geq 30.0 \mathrm{~kg} / \mathrm{m}^{2}$. Measurement of arm span was done using a flexible steel tape. Each measurement was taken twice, and the average was calculated. Arm span was taken with the participant standing against a wall, looking straight at eye level, with arms extended laterally at shoulder level. Then the steel tape was extended from the tip of the middle finger of one hand straight across the chest, to the tip of the middle finger of the other hand, and recorded to the nearest $0.1 \mathrm{~cm}$. The weight was measured to the nearest 100 grams on a digital weighing scale (Dr. Morepen Home health, Model MS-8604) with participants wearing light clothing.

Mid-upper arm circumference measurement (MUAC) was taken at the mid-point of the upper arm, halfway between the tip of the acromion process and the tip of the olecranon process, and recorded to the nearest $0.1 \mathrm{~cm}$. Two measurements each of mid-upper arm circumference of both right and left sides were taken with a measuring tape. Each measurement was taken twice, and the average was calculated.

Ethical clearance was obtained from the Ethics Committee of the All India Institute of Medical Sciences, New Delhi. Informed written consent was obtained from all participants. Any medical condition which needed management or referral was appropriately attended to.

Statistical analysis: Data was entered in MS Excel 2007, and analysis was carried out using Stata 11.0 (College Station, Texas, USA). Mid-upper arm circumference and body mass index of participants are expressed as mean \pm standard deviation (SD). Scatter diagrams and regression lines were plotted to study the relationships. Receiver operating characteristics (ROC) analysis was done and area under ROC curve was assessed. The sensitivity and specificity for different values of mid-upper arm circumference was calculated. ROC curves were made to show the ability of mid-upper arm circumference in detecting undernutrition and overweight/ obesity.

\section{RESULTS}

A total of 711 elderly persons were recruited to the study. There were 298 men (41\%) and 413 (58\%) women. Gender-wise distribution of Mid upperarm circumference and BMI across different age groups is shown in table 1 . The mean weight was $57.7 \pm 12.3 \mathrm{kgs}$, mean body mass index was $22.3 \pm 4.6\left(\mathrm{~kg} / \mathrm{m}^{2}\right)$, and mean mid-upper-arm circumference was $26.9 \pm 3.5 \mathrm{~cm}$.

Figure 1 shows the correlation between BMI $\left(\mathrm{kg} / \mathrm{m}^{2}\right)$ and mid-upper arm circumference $(\mathrm{cm})$ in participants. There is a positive correlation between BMI and MUAC seen in both men and women.

\begin{tabular}{|c|c|c|c|c|}
\hline \multicolumn{5}{|c|}{$\begin{array}{l}\text { Table 1: Gender-wise distribution of } \\
\text { subjects across different age groups } \\
(n=711)\end{array}$} \\
\hline Gender & Age (years) & $n$ & MUAC $(\mathrm{cm})$ & BMI $\left(\mathbf{k g} / \mathrm{m}^{2}\right)$ \\
\hline \multirow{4}{*}{$\begin{array}{c}\text { Males } \\
(\mathrm{n}=298)\end{array}$} & $60-64$ & 115 & $27.2 \pm 2.9$ & $22.8 \pm 4.2$ \\
\hline & $65-69$ & 85 & $26.9 \pm 3.1$ & $22.6 \pm 4.3$ \\
\hline & $70-74$ & 57 & $26.9 \pm 2.7$ & $22.0 \pm 3.6$ \\
\hline & $\geq 75$ & 41 & $26.4 \pm 3.3$ & $22.0 \pm 3.8$ \\
\hline \multirow{4}{*}{$\begin{array}{l}\text { Females } \\
(\mathrm{n}=413)\end{array}$} & $60-64$ & 218 & $27.6 \pm 3.8$ & $25.9 \pm 5.2$ \\
\hline & $65-69$ & 93 & $27.2 \pm 3.8$ & $25.2 \pm 5.3$ \\
\hline & $70-74$ & 56 & $26.0 \pm 3.2$ & $24.1 \pm 4.2$ \\
\hline & $\geq 75$ & 46 & $24.8 \pm 3.3$ & $22.0 \pm 3.7$ \\
\hline Total & & 711 & $26.9 \pm 3.8$ & $24.0 \pm 4.9$ \\
\hline
\end{tabular}

\begin{tabular}{|c|c|c|c|}
\hline Age (years) & Male & Female & Total \\
\hline $60-64$ & $0.68(<0.001)$ & $0.73(<0.001)$ & $0.70(<0.001)$ \\
\hline $65-69$ & $0.77(<0.001)$ & $0.80(<0.001)$ & $0.77(<0.001)$ \\
\hline $70-74$ & $0.38(<0.001)$ & $0.73(<0.001)$ & $0.52(<0.001)$ \\
\hline$\geq 75$ & $0.77(<0.001)$ & $0.68(<0.001)$ & $0.70(<0.001)$ \\
\hline Overall & $0.67(<0.001)$ & $0.76(<0.001)$ & $0.71(<0.001)$ \\
\hline
\end{tabular}

Data is presented as correlation coefficient (p-value)

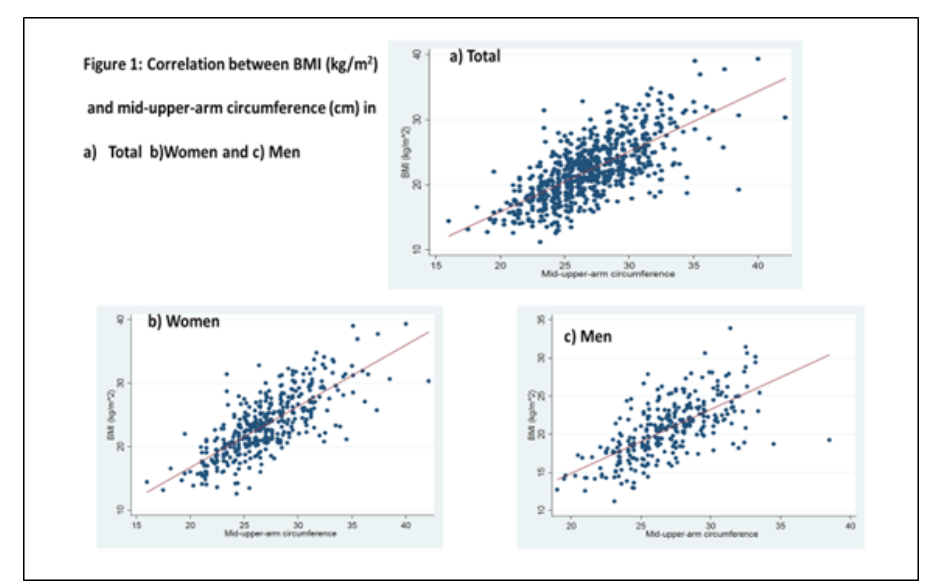

Figure 1: Correlation between BMI $(\mathrm{kg} / \mathrm{m} 2)$ and mid-upper arm circumference $(\mathrm{cm})$ in men and women.

The correlations coefficients are reported Table 2. As is evident, there is a strong correlation between mid-upper arm circumference and body mass index in both genders, across all age-groups.

Since no cut-off values have been recommended for mid-upper arm circumference (MUAC) in elderly persons, cut-off values for detecting undernutrition were explored by Receiver Operating Characteristics (ROC) curve analysis. The sensitivity and specificity for different values of MUAC was calculated using body mass index $<18.5 \mathrm{~kg} / \mathrm{m}^{2}$ as the gold standard for detecting undernutrition, and $25 \mathrm{~kg} / \mathrm{m}^{2}$ for overweight/ obesity. The cut-off levels were chosen at the value where sensitivity and specificity were maximum and closest to each other. These are shown in Table 3.

Cut-off value of mid-upper arm circumference for undernutrition was examined. When the cut-off was $25.7 \mathrm{~cm}$ for in men, the sensitivity and 


\begin{tabular}{|c|c|c|c|c|c|}
\hline $\begin{array}{l}\text { Mid-upper-arm } \\
\text { circumference }\end{array}$ & $\begin{array}{l}\text { Cut-off value } \\
\qquad(\mathrm{cm})\end{array}$ & $\begin{array}{c}\text { Sensitivity } \\
(\%)\end{array}$ & $\begin{array}{c}\text { Specificity } \\
(\%)\end{array}$ & $\begin{array}{l}\text { Likelihood } \\
\text { Ratio }\end{array}$ & $\begin{array}{c}\text { Area under } \\
\text { curve }(95 \% \mathrm{Cl})\end{array}$ \\
\hline \multicolumn{6}{|l|}{ Undernourished } \\
\hline Men (n=267) & $<25.7$ & 80.2 & 78.6 & 3.9 & $0.85(0.80,0.90)$ \\
\hline Women $(n=259)$ & $<24.3$ & 79.0 & 79.0 & 3.8 & $0.86(0.81,0.91)$ \\
\hline Total $(\mathrm{n}=526)^{\star}$ & $<25.2$ & 75.7 & 75.1 & 3.1 & $0.83(0.79,0.87)$ \\
\hline \multicolumn{6}{|l|}{ Overweight \& obese } \\
\hline Men $(\mathrm{n}=351)$ & $\geq 28.5$ & 69.2 & 66.5 & 2.1 & $0.76(0.67,0.84)$ \\
\hline Women $(n=212)$ & $\geq 27.5$ & 77.4 & 74.6 & 3.1 & $0.84(0.80,0.88)$ \\
\hline Total $(\mathrm{n}=563)^{\star *}$ & $\geq 28.2$ & 73.5 & 73.0 & 2.7 & $0.80(0.76,0.83)$ \\
\hline
\end{tabular}

* The 185 persons who were overweightlobese were excluded from this analysis;

${ }^{* *}$ The 148 persons who were undernourished were excluded from this analysis.

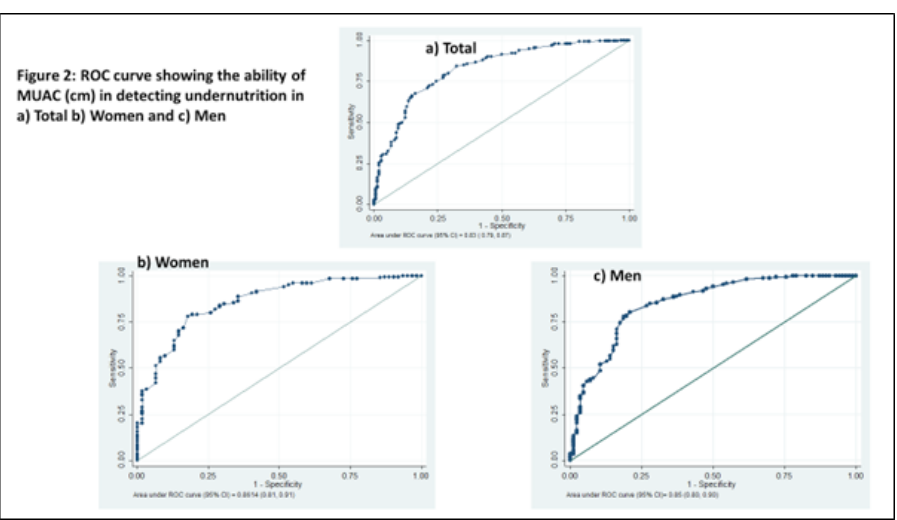

Figure 2: ROC curves showing the ability of mid-upper arm circumference in detecting undernutrition in men and women.

specificity was $80.2 \%$ and $78.6 \%$ respectively. In women, with a cut off value $24.3 \mathrm{~cm}$ both the sensitivity and specificity were $79 \%$. Overall, for both men and women combined, a cut-off value of $25.2 \mathrm{~cm}$ yielded a sensitivity of $75.7 \%$ and specificity of $75.1 \%$.

For estimating the higher end of the nutrition spectrum, we have combined overweight and obese persons for estimating the cut-off values. Using the cut-offs $28.2 \mathrm{~cm}$ for both men and women combined, the sensitivity and specificity were $73.5 \%$ and $73.0 \%$, respectively. When analysis was done separately by gender, a cut-off value of $28.5 \mathrm{~cm}$ for men gave a sensitivity of $69.2 \%$ and specificity of $66.5 \%$. Whereas for women, at $27.5 \mathrm{~cm}$, the sensitivity and specificity were $77.4 \%$ and 74.6 $\%$ respectively.

ROC curves were made to show the ability of mid-upper arm circumference in detecting undernutrition and overweight/ obesity. The ROC curves for men and women separately are shown in Figure 2 and Figure 3 respectively. When the cut-off was $25.2 \mathrm{~cm}$, the area under ROC curve (AUC) was 0.83 (95\%CI $0.79,0.87)$ for detecting undernutrition in both men and women. Whereas for overweight and obesity, with $28.2 \mathrm{~cm}$ cut-off, area under ROC curve was 0.80 (95\% CI 0.76, 0.83).

\section{DISCUSSION}

This was a community-based study among 711 elderly persons in urban Delhi. It was conducted with the objective of examining the relationship between body mass index and mid-upper arm circumference. The study also attempted to identify an appropriate cut-off for detecting undernutrition and overweight/obesity by using mid-upper arm circumference

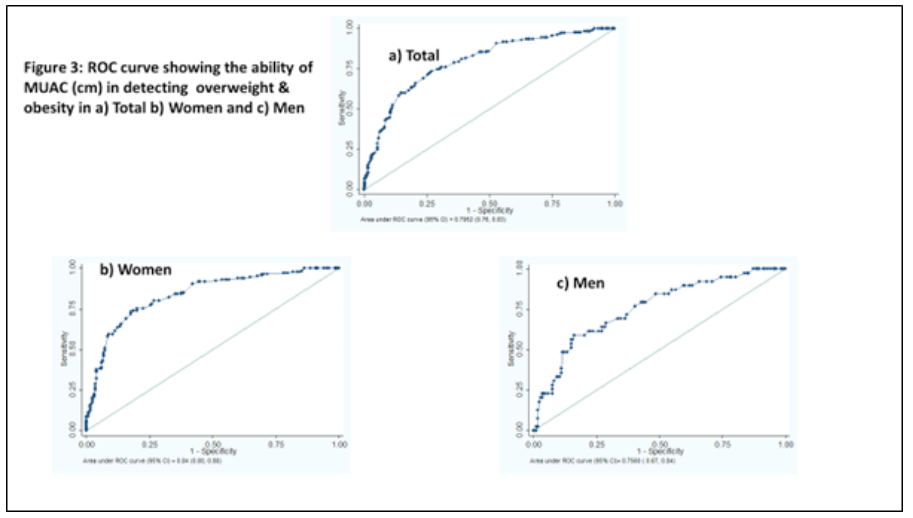

Figure 3: ROC curves showing the ability of mid-upper arm circumference in detecting overweight and obesity in men and women.

in elderly persons in urban India. This study shows that there is a positive correlation between body mass index and mid-upper arm circumference in both men and women. Similar findings have been reported in other studies. A study from Spain reported secondary data analysis of anthropometric data of patients hospitalised over the period 2004-2013. The study reported that mid-upper arm circumference correlates suitably with body mass index, with the following equation (simple linear regression): $\mathrm{BMI}=-0.042+0.873 \times$ MUAC $(\mathrm{cm})\left(\mathrm{R}^{2}=0.609\right)$, with a Pearson $r$ value of $0.78(\mathrm{p}<0.001) .{ }^{13}$ Another study in Vietnam reported a positive correlation between mid-arm circumference and body mass index. ${ }^{14}$ Similar findings were seen in a multicentre cross-sectional study at nine hospitals in Indonesia. ${ }^{15}$ A study among elderly population from Thailand from four rural communities among 2324 subjects aged 60 years old and over, reported that the mid-arm circumference had the strongest relationship with body mass index $(r=0.76-0.87, \mathrm{P}<0.001) .{ }^{16}$ Similar findings were reported among Portuguese elderly persons living in Brazil. ${ }^{17}$ However, few studies from India could be found which reported the relation between mid-upper arm circumference and body mass index among elderly persons. A study from rural Haryana showed strong positive correlations of body mass index with mid-upper arm circumference, triceps skinfold thickness and calf circumference, with the strongest correlation between body mass index and mid-upper arm circumference $(\mathrm{r}=0.88) .{ }^{4}$ A study among Mumbai slum population in elderly showed similar results. ${ }^{18}$

This study also tried to establish a reasonable cut-off point for mid-upper arm circumference for undernutrition, equivalent to body mass index $\leq$ 
$18.525 \mathrm{~kg} / \mathrm{m}^{2}$, and body mass index $\geq 25 \mathrm{~kg} / \mathrm{m}^{2}$ for overweight/obesity. In this study, it was seen that cut-off of $25.2 \mathrm{cms}$ was shown to be the optimum level for both men and women, which yielded a sensitivity and specificity of $75.7 \%$ and $75.1 \%$, for undernutrition Whereas a study from rural Haryana recommended a cut-off value $26.1 \mathrm{~cm}$ for mid-upper arm circumference for detecting undernutrition. ${ }^{4}$ A study from Mumbai reported similar cut-off $25.0 \mathrm{~cm}$ for men and $24.3 \mathrm{~cm}$ for women. ${ }^{18}$ Higher cut-off values were obtained in a multi-centric study in Indonesia where the cut off value of upper arm circumference for elderly men and women is $>27 \mathrm{~cm} .{ }^{15} \mathrm{~A}$ study from Spain showed that the mid-upper arm circumference value $22.5 \mathrm{~cm}$ presented a sensitivity of $67.7 \%$, specificity of $94.5 \%$, and a correct classification of $90 \%{ }^{19}$ Using the cut-offs $28.2 \mathrm{~cm}$ for both men and women combined, the sensitivity and specificity were $73.5 \%$ and $73.0 \%$, respectively for overweightlobesity.

Limitations: This study was carried out in a small population which may not be representative for different populations in India. There is need to create regional specific geriatric reference values or standards of anthropometry across ethnicities and regions for nutritional assessment methods of older persons.

\section{CONCLUSION}

The study authenticates that mid-upper arm circumference correlates positively and significantly with body mass index. In situations where body mass index cannot be determined by weight or height, mid-upper arm circumference can be used as a proxy for estimating the nutritional status. Mid-upper arm circumference values of $25.7 \mathrm{~cm}$ in men and $24.3 \mathrm{~cm}$ in women are useful cut-off points for screening for under nutrition, while $28.5 \mathrm{~cm}$ in men and $27.5 \mathrm{~cm}$ in women could be useful indicators for overweight/obesity.

\section{CONFLICT OF INTEREST}

The authors declare no conflict of interest.

\section{ABBREVIATION USED}

MUAC: Mid Upper Arm Circumference; ROC: Receiver Operating Characteristics; AUC: Area Under Curve.

\section{SUMMARY}

The study was done to find out the association between mid-upper arm circumference (MUAC) and body mass index (BMI) and to estimate the cut-off values of MUAC in elderly. . Positive correlation was seen between BMI and MUAC in men and women. The study authenticates that MUAC correlates positively and significantly with BMI. MUAC values of $25.7 \mathrm{~cm}$ in men and $24.3 \mathrm{~cm}$ in women are useful cut-off points for undernutrition, while $28.5 \mathrm{~cm}$ in men and $27.5 \mathrm{~cm}$ in women could be useful for overweight/obesity.

\section{REFERENCES}

1. Preedy VR. Handbook of Anthropometry. Physical measurement of human form in health and disease. Dordrecht: Springer. 2012.

2. World Health Organization. Physical status: The use and interpretation of anthropometry. (Report of a WHO Expert Committee; Technical Report Series No.854). Geneva, Switzerland: World Health Organization. 1995.

3. Bryna S, Marie JK, Sylvie N. Anthropometric changes over 5 years in elderly Canadians by age, gender, and cognitive status. J Gerontol. 2001;56A(8):M483-M8.

4. Jamir L, Kalaivani M, Nongkynrih B, Misra P, Gupta SK. Anthropometric Characteristics and Undernutrition Among Older Persons in a Rural Area of Northern India. Asia Pac J Public Health. 2015;27(2):NP2246-58. DOI: https:// doi.org/10.1177/1010539513490191

5. Anthropometric measures and nutritional status in a healthy elderly population Sergio Sánchez-García, Carmen García-Peña, María Ximena DuqueLópez, Teresa Juárez-Cedillo, Alma Rosa Cortés-Núñez,Sandra Reyes Beaman. BMC Public Health. 2007;7:2. doi:10.1186/1471-2458-7-2

6. Machin, D, Campbell MJ, Fayers P, Pinol A. Statistical Tables for the Design of Clinical Studies, Second Edition. Blackwell, Oxford. 2011.

7. Jamir L, Kalaivani M, Nongkynrih B, Misra P, Gupta SK. Relationship between arm span and height among elderly persons in a rural area of Ballabgarh, Haryana. Indian Journal Medical Specialties. 2013;4(2):248-53.

8. Kwok T, Whitelaw MN. The use of armspan in nutritional assessment of the elderly. J Am Geriatr Soc. 1991;39(5):492-6.

9. Manonai J, Khanacharoen A, Theppisai U, Chittacharoen A. Relationship between height and arm span in women of different age groups. J Obstet Gynaecol Res. $2001 ; 27(6): 325-7$.

10. Nygaard HA. Measuring body mass index (BMI) in nursing home residents: the usefulness of measurement of arm span. Scand J Prim Health Care. 2008;26(1):46-9.

11. Ofluoglu D, Unlu F, Akyuz G. Relationship between arm span and height in postmenopausal osteoporotic women. Rheumatol Int. 2008;28(8):737-41

12. Rabe B, Thamrin MH, Gross R, Solomons NW, Schultink W. Body mass index of the elderly derived from height and from armspan. Asia Pac J Clin Nutr. 1996;5(2):79-83.

13. Benítez Brito N, Suárez Llanos JP, Fuentes Ferrer M, et al. Relationship between Mid-Upper Arm Circumference and Body Mass Index in Inpatients. Aguilera Al, ed. PLoS ONE. 2016;11(8):e 0160480. doi:10.1371/journal.pone.0160480.

14. Tam TT, Gross R, Lukito W, Rumawas JS. Chronic energy deficiency and relative abdominal over fatness coexist in free-living elderly individuals in $\mathrm{Ho}$ Chi Minh City, Vietnam. Asia Pac J Clin Nutr. 1999;8(2):129-35.

15. Setiati S, Istanti R, Andayani R, Kuswardhani RA, Aryana IG, Putu ID, et al. Cut-off of anthropometry measurement and nutritional status among elderly outpatient in Indonesia: multi-centre study. Acta Med Indones. 2010;42(4):224-30

16. Assantachai $P$, Yamwong $P$, Lekhakula S. Alternative anthropometric measurements for the Thai elderly: Mindex and Demiquet. Asia Pac J Clin Nutr. 2006;15(4):521-7.

17. Menezes TN, De Fátima Nunes Marucci M. Anthropometry of elderly people living in geriatric institutions, Brazil. Rev Saude Publica. 2005;39(2):169-75. Portuguese.

18. Manandhar MC, Anklesaria PS, Ismail SJ. Weight, skinfolds and circumference characteristics of poor elderly people in Mumbai, India. Asia Pac J Clin Nutr. 1997;6(3):191-9.

19. Brito NB, Llanos JP, Fuentes Ferrer M, Oliva García JG, Delgado Brito I, PereyraGarcía Castro F, et al. Relationship between Mid-Upper Arm Circumference and Body Mass Index in Inpatients. PLoS One. 2016;11(8):e0160480. doi: 10.1371/ journal.pone.0160480

Cite this article : Goswami AK, Kalaivani M, Gupta SK, Nongkynrih B, Pandav CS. Usefulness of Mid-Upper Arm Circumference in Assessment of Nutritional Status of Elderly Persons in Urban India. Int J Med Public Health. 2018;8(1):34-37. 